\title{
Antik Yapı Malzemesi Olarak Tuğla ve Kiremit: Boğsak Adası Bizans Yerleşimi Örneklemi
}

Murat Eroğlu

Makale Geliş Tarihi: 12.10.2017

Yrd. Doç. Dr. Ali Akın Akyol

Yayına Kabul Tarihi: 13.11.2017

\section{Özet}

Bu çalışmada antik yapı malzemesi kil kullanılarak üretilen tuğla ve kiremit tanımlanmış, fiziksel özellikleri, üretim biçimleri, süreci ve üretimi etkileyen faktörler hakkında bilgiler verilmiștir. Bunun yanında tuğlanın tarihçesi ele alınmış, malzeme olarak geliștirilmesi esnasında rol oynayan toplumlar yanında tuğlanın tarihçesi ele alınmış, malzeme olarak geliştirilmesi esnasında rol oynayan toplumlar
hakkında kültürel ve sosyal bilgiler aktardığına değinilmiştir. Ayrıca tuğlaların fiziksel ve kimyasal özellikleri anlatılmış, Boğsak Adası Yerleşimi tuğla ve kiremit örneklemine uygulanan fiziksel ve petrografik özellikleri belirlemeye yarayan analizlerin sonuçları paylaşılmıştır. Bir tez araştırma projesi kapsamında ele alınan Boğsak Adası tuğla/kiremit örnekleri belgelenmiş ve gruplandırılmıştır. Tuğla/kiremit örneklerinin fiziksel özellikleri fiziksel testlerle, petrografik özellikleri de ince kesitleri hazırlanarak petrografik optik mikroskop analizi ile tespit edilmiştir. Kısaca bu çalışma, tuğla/ hazırlanarak petrografik optik mikroskop analizi ile tespit edilmiştir. Kısaca bu çalışma, tuğlal
kiremitlerin yapısal özelliklerini, tarihsel gelişimini ve Boğsak Adası yerleşimi örneklemi ışığında fiziksel ve petrografik analizlerini içermektedir.

Anahtar Kelimeler: Tuğla, Tuğlanın Malzeme Özellikleri, Boğsak Adası Yerleşimi, Fiziksel Testler, Petrografik Ince Kesit Analizi

\section{BRICK AND TILE AS ANTIQUE BUILDING MATERIAL: BOĞSAK ISLAND} BYZANTIUM SETTLEMENT SAMPLING

\section{Abstract}

In this study, bricks and tiles which were produced with the use of clay, an ancient contruction material, were described and informations about their physical characteristics, manufacturing methods and processes and the factors affecting its production were given. In addition to these, the history of brick was dealt with and it was highlighted that brick conveys cultural and social the history of brick was dealt with and it was highlighted that brick conveys cultural and social
information about the communities which had played a role in its development. Also, the significant physical and chemical characteristics of the brick are explained and the results of the analyses used to determine the physical and petrographic features which were applied to the samples from Boğsak Island Settlement. The brick/tile samples, which were examined withing the scope of a thesis research project have been documented and classified. The physical properties of the brick I tile samples were determined by physical tests and the petrographic features were determined by petrographic optical microscope analysis. In short, this study addresses the physical features of bricks/tiles, their historical development and their physical and petrographic analyses in the light of the sampling of Boğsak Island Settlement.

Keywords: Brick, Brick Material Characteristics, Boğsak Island Settlement, Physical Tests, Petrographic Thin-Section Analysis 


\section{Giriş}

1.1 Tuğlanın Tanımı ve Özellikleri

Tuğlanın ham maddesi kildir. Kilden yapılan malzemeleri pişirilmiş ve pişirilmemiş olarak ikiye ayırmak mümkündür. Pişirilmemiş malzemenin başında kerpiç gelmektedir. Pişirilmiş malzemelere de tuğla, kiremit ve künkler örnek verilebilir. Tuğla ve kiremidin üretim şekli aynı olup sadece kalıplama sistemleri farklıdır. Tuğlalar üretim şekillerine göre de el (harman) tuğlası ve fabrika tuğlası olarak ikiye ayrılmaktadır (Şimşek, 2003: 103113).

Tuğla üretim kademeleri hammadde hazırlanması, şekillendirme, kurutma, pişirme ve ambalajlama-sevk olmak üzere 5 aşamadan oluşmaktadır. Dinlendirme, hammadde hazırlama aşamalarının en önemlisi olup üretilen malzemenin kalitesini etkileyen çok önemli bir unsurdur. Kurutma, kil içinde mevcut ve şekillendirmeye uygun bir kıvama getirmek için katılan suyun değişik yöntemlerle bünyeden çıkarılma işlemidir. Pişirme, tuğla üretimindeki en son aşamadır. Kilin kuruma aşamasında, serbest haldeki suyunu ve sonradan emdiği suyu kaybetmesinden dolayı boyutlarında küçülme (çekme) olur. Pişirme sırasında kil kimyasal reaksiyonlara maruz kalır. $300^{\circ} \mathrm{C}$ civarında organik maddeler tamamen yanar, $450-650^{\circ} \mathrm{C}$ arasında molekül suyunu kaybeder. $850-950^{\circ} \mathrm{C}$ arasında kil hamurunun pişmesiyle oluşan bu yeni malzeme artık sert, şeklini değiştirmeyen, belirli mukavemet ve renge sahip bir üründür (Işık, 2010: 55).

Tuğlanın özellikleri tuğla toprağının karışım oranına, üretim tekniğine, pişirilme şekline ve pişirildiği sıcaklık derecesine göre değişir. Günümüz tuğlalarında harman tuğlalarının yüksekliği 5,4 - 6,3 cm; genişliği 9,2 $11,8 \mathrm{~cm}$ ve boyu 20,5 - 22,7 cm arasında değişmektedir. Bu tuğlaların basınç dayanımları 7,5 MPa'dan az, su emme kapasitesi ve donmaçözülme dayanımları da düşüktür. Fabrika tuğlalarında su emme değerleri düşük olup en çok \%18'dir. Bu tuğlaların basınç dayanımları 6-10 MPa arasında değişmekte iken yoğunluklu tuğlalarda bu değer $24 \mathrm{MPa}$ kadar çıkmaktadır (Şimşek, 2003: 103-120).

Tuğla, toprak malzemenin temini ve kullanımı kolay olması yanı sıra ucuzluğu nedeniyle yaygın olarak kullanılmaktadır. Tuğlanın üretim için uygun kilin bulunduğu her yerde kolaylıkla üretilmesi, birim ağırlığının taş ve betona göre daha az, ısı yalıtımının daha yüksek oluşu, standart boyutları nedeniyle inşa sırasında kolay kullanılması ve duvar kalınlığının ince tutulması gibi avantajları vardır. Ayrıca tekniğine uygun olarak üretildiğinde basınç dayanımları, su emme, dona dayanıklııı ve dış etkilere dayanıklılıkları da oldukça yüksektir (Özışık, 2000; Şişman, Kocaman ve Gezer, 2006: 34).

\subsection{Tuğlanın Tarihçesi}

Kerpiç, toprağın saman ve suyla karıştırıldıktan sonra kalıplara dökülerek önce gölgede daha sonra güneşte kurutulmasıyla elde edilen en eski yapı malzemelerindendir. Kerpiç yapımında ilk aşama, kilin yoğurulup elde hazırlandığı aşamadır. İkinci aşama ise kalıplarda biçimlendirildiği ve güneşte kurutulduğu aşamadır. Bu iki aşamada üretilen kerpiçler güneş altında kurutulduğu için sert iklim koşullarında daha kolay bozulmaktadır. Seramik pişirme yöntemlerini bilen insanlar, kerpici de bu nedenle pişirmiş olmalıdır ki bu da üçüncü bir aşamayı, tuğla üretimini temsil etmektedir. Yapı ve süsleme malzemesi olarak tuğla, üretiminin kolaylığı ve düşük maliyeti ile yüzyıllardan beri kullanılmaktadır (Akyol, Yıldırım, Erten ve Kadıoğlu, 2013; Akyol, Kadıoğlu ve Özyıldırım, 2014; Bakırer, 1981: 3).

Tuğlanın kullanımında bölgesel şartlar da önemlidir. Buna göre Anadolu, Kafkaslar, Girit ve Kıbrıs'ta taş kaynaklarının yoğunluğu nedeniyle taş ile yapılmış yapılar dikkati çekerken; Mezopotamya, İran, Orta Asya ve Mısır'da ise taşın sınırlı olmasından dolayı onun yerini tuğla almıştır. Bu bölgelerde taş ancak tuğla örgüyü sağlamlaştırmada kullanılmıştır (Bakırer, 1981: 3). Tuğla yapımı ile ilgili en eski üretim bilgilerine antik kaynaklardan Mısır fresklerinde ve yazılı malzemelerinde rastlanmaktadır (Görsel 1a-c).

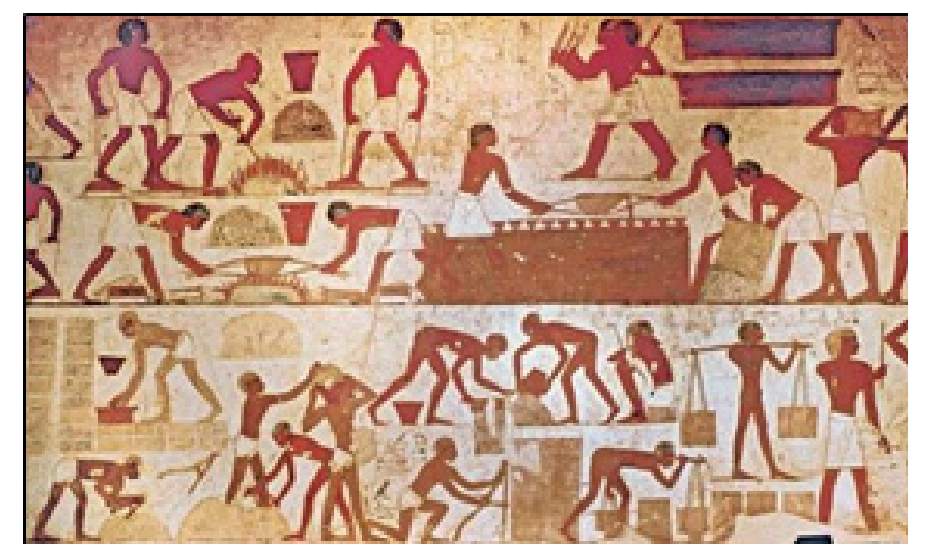




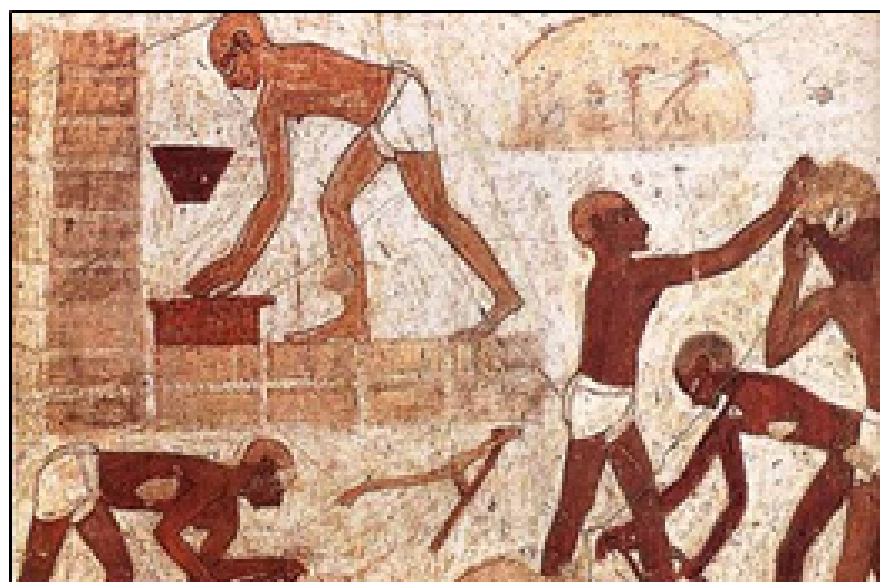

Görsel Ib. 18. Hanedanlık dönemine ait Firavun Rekhmire'in (M.Ö. 1479-1425) mezarından tuğla üretimine ait fresk detayı

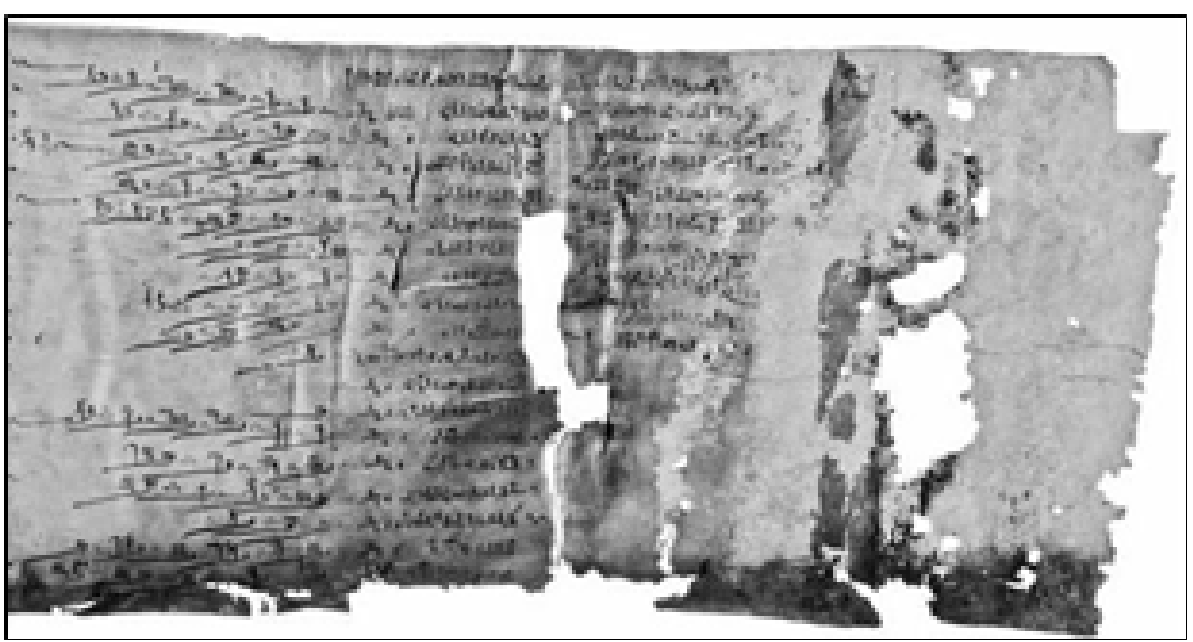

Görsel Ic. II. Ramses'in 5. yılına (M.Ö. I274) ait tuğla yapımını içeren deri rulo

Kerpicin pişirilmesi ile tuğla elde edilmiş ve tarihte günümüzden yaklaşık 5000 yıl öncesinde Erhanedanlar Dönemi'nde büyük tapınak, saray yapıları yapılırken tuğla kullanılmıştır. Tuğla ile yapılmış en önemli yapı M.Ö. 2112-2095 kral Ur-Nammu'ya ait zigurattır (Roaf, 1996: 104; Bakırer, 1981: 2) (Görsel 2a). Bu dönemde bazı tuğlaların üzerinde çivi yazıları da bulunmaktadır. Yeni Babil Dönemi'nde (M.Ö. 6. yüzyıl) sırlı tuğlalarla yapılmış İştar kapısına ait panellerin bir kısmı ile erken döneme ait yazıtlı tuğla örnekleri İstanbul Şark Eserleri Müzesi'nde de sergilenmektedir (Benzel, 2010) (Görsel 2b). Roma döneminde M.S. 1. yüzyıldan itibaren özellikle Augustus Dönemi'nde (M.Ö. 27-M.S. 14) yapılarda tuğla kullanımı
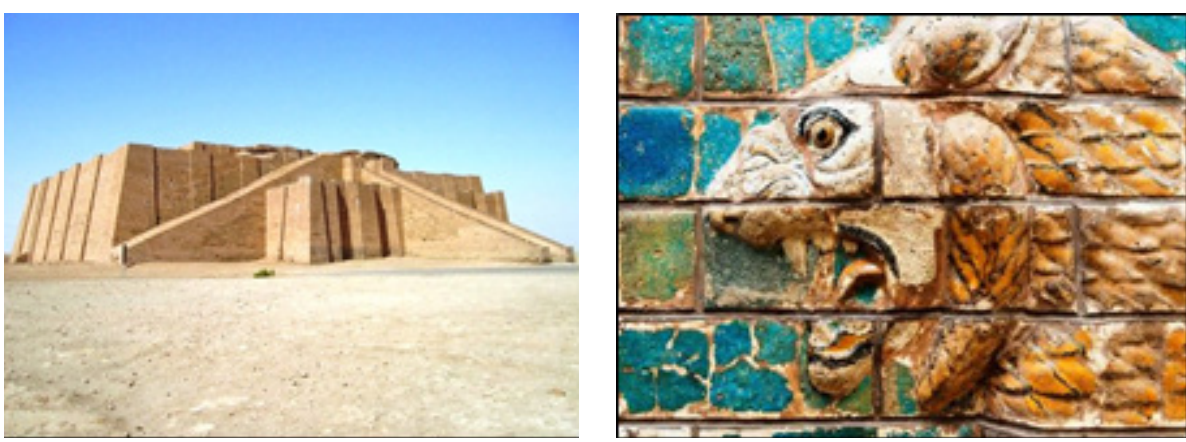

Görsel 2a. M.Ö. 21 I 2-2095 Kral Ur-Nammu'ya ait tuğla zigurat. (Solda)

Görsel 2b. Yeni Babil Dönemi’nde (M.Ö. 6. yüzyıl) sırlı tuğlalarla yapılmış Iştar Kapısı

görülmeye başlanmıştır. Bu dönemde Anadolu'da Bergama'da Hadrian Hamamı ve Serapis Tapınağı'nda, Ankara'da Caracalla Hamamı'nda ve Millet'te Faustina Hamamı'nda da duvar örgülerde tuğla kullanılmıştır. Tuğla tonozlu yapılara da Anadolu'da Efes, İzmir Smyrna, Aspendos, Elaiussa Sebaste ve Amorium yerleşmelerinde Roma Dönemi yapılarında rastlanılmaktadır (Dodge, 1984: 10-15).

Tuğla ile ilgili diğer bir konu da tuğla üzerindeki baskılardır. Bu baskılar tuğla üretimi, üretim yeri, üreten aileler hakkında ipucu vermektedir. Tuğla üretimi, tuğla fabrikası ve dağıtımı üzerine yazılı kaynaklardan önemli bilgiler edinilmektedir. Bu konuda en önemli ve ilginç karakterlerden birisi de tuğla üreten Domitia Lucilla Minor'dur. Domitia Lucilla Minor, tuğla fabrikası olan zengin Domitia ailesinin kızı ve kral Marcus Aurelius'un da annesidir (Filippi 2007: 205). Roma'da Tiber Nehri kenarında tuğla fabrikası bulunmaktaydı ve Roma çevresindeki birçok yapıda onun fabrikasında üretilen tuğlalar kullanılmaktaydı. Bu yapılardan en önemlileri Pantheon Tapınağı, Traianus Pazarı ve Colosseum'dur (Kamm ve Graham 2014: 99) (Görsel 3a,b). 


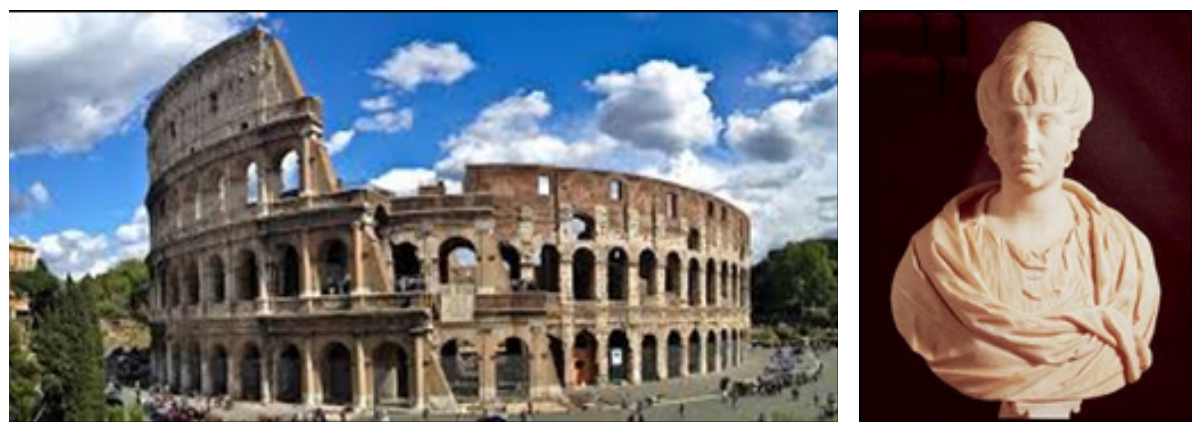

Görsel 3a. Colosseum (M.S. 72, Roma) (Solda)

Görsel 3b. Tuğla İşliğinin Sahibi Domitia Lucilla Minor (Sağda)

Roma Dönemi'nde tuğlanın ikincil kullanımı da yaygınlaşmışır. Buna göre tuğla kırıkları harç ve sıva içerisine katılarak bağlayıcı etkisinin yanı sıra, suyu tutma etkisinden de yararlanılmıştır (Vitruvius, 1993: 146).

Roma Dönemi tuğlaları hakkında bilgileri dönemin mimarı Vitruvius'tan öğrenmek mümkündür. Vitruvius, yapılarda kullanılan tuğla malzemenin yapım nitelikleri ve kullanım biçimleri ile ilgili ayrıntılı bilgiler verir. Tuğla yapımında makbul olan malzemenin beyaz kalkerli kil, kırmızı kil ya da kaba taneli çakıllı kil olması gerektiğini; ince kilin dış etkenlerden etkilenerek dağıImaya daha elverişli olduğunu belirtir. Aynı zamanda bu tip malzemeler diğerine göre daha hafiftir ve daha kolay çalışılmaktadır (Vitruvius, 1993: 30).

Vitruvius tuğlanın yapım ve uygulama teknikleri hakkında da bilgi vermektedir (Vitruvius 1993:29). Buna göre:

Tuğlalar, düzgün kuruyabilmeleri için baharda veya sonbaharda yapılmalıdır. Yazın yapılanlar, kızgın güneş dış yüzeylerini kurutup içlerini nemli bıraktığından kusurlu olurlar. Kururken meydana gelen çekme, daha önce kurumuşolan kısımlarda çatlaklar oluşturarak tuğlaları zayıflatır. Tuğlalar, kullanılmalarından iki yıl önce yapılırlarsa en yararlı olur; çünkü daha az zamanda kurumazlar. Taze, tam kurumamış tuğlalar bir duvarda kullanıldığında, duvar sıvası sertleşerek kalıı bir kitleye dönüşür; buna karşın, tuğlalar oturduktan sonra sıva ile aynı yüksekliği tutturamazlar; çekerken oluşan hareket sıvaya yapışmalarını önlediğinden sıvadan koparlar. Bu nedenle, artık duvardan kopan sıva, çok ince olduğundan tutunamaz ve düşer; duvarların kendileri de bu oturmadan zarar görebilirler. Bu o denli doğrudur ki, Utica'da duvarlar yapılırken, yalnızca yetkililer tarafından onaylanmış beş yı önce yapılmış tuğlalar kullanılır.
Vitruvius o dönemde kullanılan tuğla tipleri hakkında da bilgi vermektedir, buna göre üç tip tuğla vardır: Birincisi, Yunancada Lidya türü olarak bilinen bir buçuk ayak uzunluğunda ve bir ayak genişliğinde olanıdır. Diğer iki tür ise yapılarda kullanılanlardır. Doron ( $\Delta \omega \rho \mathrm{pov})$ Yunancada hem avuç hem de armağan anlamına gelmektedir, çünkü dönemde armağanlar her zaman avuçla sunulmaktadır. Beş avuç karelik tuğlaya "pentadoron", dört avuç kare olanına "tetradoron" denmektedir. Kamu binalarında genellikle "pentadoron", özel yapılarda ise "tetradoron" tipi tuğlalar tercih edilmektedir (Vitruvius, 1993: 30; Adam, 1999: 147) (Görsel 4).

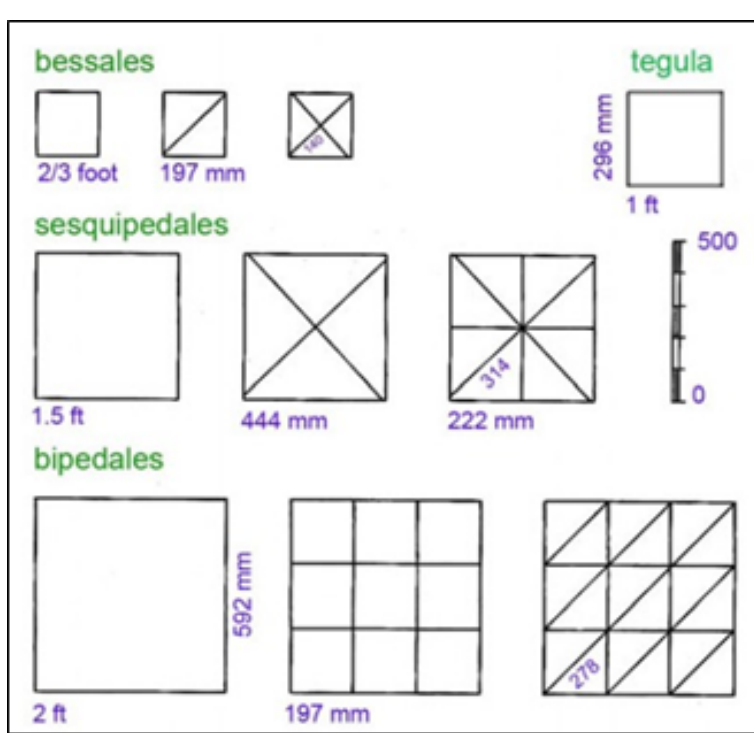

Görsel 4a. Roma Dönemi tuğla boyutları

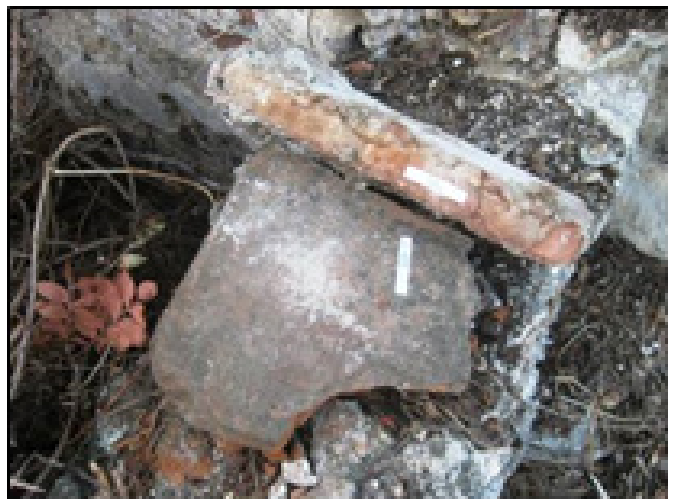

Görsel 4b. Boğsak adası tuğla örnekleri (MBA-B9) 
Molozla yapılan ve incelikle tamamlanan duvar türlerinin hiçbiri zaman geçtikçe yıkılmaktan kurtulamaz. Bu yüzden, ortak duvarları değerlendirmek üzere seçilen bilirkişiler değerlendirmelerini inşaatın maliyetine göre yapmazlar; fakat her davada, yazılı sözleşmeye bakarak, duvarın ayakta durduğu her yıl için maliyetin seksende birini çıkarırlar ve geri kalan kısmının ödenmesine karar verirler. Böylelikle, bir yerde bu tür duvarların seksen yıldan fazla dayanmayacağını belirtmiş olurlar. Ancak tuğla duvarlara gelince, ayakta kaldıkları sürece, hiçbir kesinti yapılmaz ve değerlendirmeleri her zaman inşaatın maliyetine göre yapılır. Bu yüzden, bazı eyaletlerde kamu binalarıla özel konutların yanı sıra kral evlerinin de tuğladan yapıldıklarını görürüz.

Vitruvius yapılardaki duvarların kullanımı ve dönemin imar yasaları hakkında bilgi verirken aynı zamanda kentlerin nüfusun artması üzerine yer sıkıntısından dolayı çok katlı konutların yapıldığı ve bunlarla tuğla yapıların ilişkisi hakkında bilgi vermektedir (Vitruvius, 1993:40).

\section{Buna göre:}

Ülkenin yasaları kamu mülkiyetindeki yerlerde bulunan duvarların bir buçuk ayaktan kalın olmasını yasaklamaktadır. Diğer duvarlar yer kazanmak için aynı kalınlıkta yapılırlar. Diğer yandan tuğla duvarlar, iki veya üç tuğla kalınlığında olmadıkça, bir kattan fazlasını taşıyamazlar; bir buçuk ayak kalınlığındaki duvarlarda bu kesinlikle olası değildir. Ancak, kentin bugünkü önemi ve sınırsız nüfusu nedeniyle konut sayısının sürekli olarak artırılması gereklidir. Sonuçta, zemin katları, kentte yaşayan büyük nüfusu barındırmaya yeterli olmadığından, sorunun yüksek binalarla çözülmesini zorunlu kılıyor. Taş ayaklar, fııınlanmış tuğla duvarlarve moloz bölmelerle kat kat yükselen bu bina kümelerinin üst katları, çok yararlı bir bi $\neg$ çimde odalara bölünebiliyor. Kentin surlar içindeki yerleşim alanı böylelikle çok katlı yapılarla çoğaldığından, Roma halkı, içinde yaşayabileceği mükemmel yerleri kolaylıkla bulmaktadır. Yer darlığının kent içinde tuğla duvar kullanımını nasıl engellediği şimdi açıklanmış bulunmaktadır.

Roma döneminde tuğlaların üretimi, üretildiği yer ve üreten kişiler hakkında bilgi edinirken ayrıca tuğla üretiminde geçen iş günü, ödenecek miktar ve bunların üretildiği yerden taşınması gibi konular hakkında da bilgi edinmek mümkündür. Buna göre Roma duvar tekniklerinden "opus incertum" ile "opus reticulatum" yapımında kullanılan malzeme, iş günü, ödenecek miktar hakkında bilgi verilmektedir. Roma'da Traianus Pazarı ve Caracalla Hamamı'nın yapımında kullanılmak üzere tüf, harç, pozzolan, tuğla malzemenin sağlanması, üretimi ve taşınması hakkında bilgi verilirken malzemelerin nereden getirildiği hakkında da bilgi edinilmektedir
(Mattingly ve Salmon, 2002: 240).

Roma dönemi kaynaklarında tuğla üzerine bilgiler edindiğimiz gibi Bizans Dönemi'nde de tuğla üretimi, tuğla yapımcısı, kil üreticisi ve tuğla fırınlarının konumları hakkında bilgi edinmek mümkündür. Özellikle Constantinapolis ve çevresindeki Bizans Dönemi yapılarının taşıyıcı duvarları ve örtü sistemlerinde geniş çaplı tuğla kullanımı görülür. Giderek bu yapısal kullanım Geç Bizans Dönemi yapılarında yüzey süslemelerinde ağırlıklı olarak kullanmasıyla devam eder (Bakırer, 1981: 3-7).

Bizans döneminde pek çok şehirde, şehrin dışında ya da daha az nüfusa sahip alanlarında tuğla fırınları (ergasteriaların) kurulmuştur. Fırınlardan çıkan duman miktarı ve fırının ürettiği koku, şehir ile işlikler arasında bir miktar mesafe olması gerekliliğini de doğurmuştur. Kaynaklarda, tuğla üreticisinden ostrakarioi (kil üreticisi) ya da keramopoioi (tuğla yapımcısı) olarak bahsedilmektedir. Theopanes'e göre, Constantinapolis'deki su kemerlerinin yeniden inşası için Yunanistan'dan 500 ostrakarioi (kil üreticisi), adalardan ise 200 keramopoioi (tuğla yapımcısı) getirilmiştir. Tuğlanın ticari amaçlı taşınmasında kolaylık sağlamak ve yapımı sırasında yerleşimden uzak olmak amacıyla üretim fırınlarının genellikle deniz kenarındaki sahil kesimlerine kurulduğunu bilinmektedir. Benzer bir örnek olan Athos Dağı'ndaki Larva Manastırı'nda, tuğla üretimi için deniz kenarında bir ergasterion yer almaktadır (Mergen, 2010: 33-35). Deniz kenarında sahillerde tuğla fırınları kurulup buradan teknelerle taşındığı düşünülse de batık araştırmalarında tuğla ele geçmemiş, buna karşın künk ele geçmiştir. Buna göre Marmara Denizi'nde Küçük Ada Batığı'nda yüzlerce künk tespit edilmiş̧ir. Bu batık M.S. 7. yüzyıla tarihlendirilmiştir ve şu ana kadar tuğlanın teknelerle taşındığını gösteren kanıt bulunamamışken bu örnek künk taşımacılığı açısından önemlidir (Günsenin, 1996: 369).

\section{Boğsak Adası Yerleşimi}

Isauria Bölgesi'nin güney kıyılarında, Mersin ili sınırları içinde, Taşucu'nun 8 km güneybatısında yer alan Boğsak Adası, Boğsak Koyu'nun güney girişinin 300 metre açığında yer alan yaklaşık 7 hektar yüzölçümünde, kuzey-güney yönünde yaklaşık $500 \mathrm{~m}$, doğu-batı yönünde $250 \mathrm{~m}$ uzunluğa sahip tarıma elverişsiz küçük bir kayalıktır. Bu bölgenin en az bilinen ve en iyi korunmuş yerleşimlerinin başında gelmektedir (Görsel 5) (Varinlioğlu, 2011: 172; Varinlioğlu, 2012: 370). 

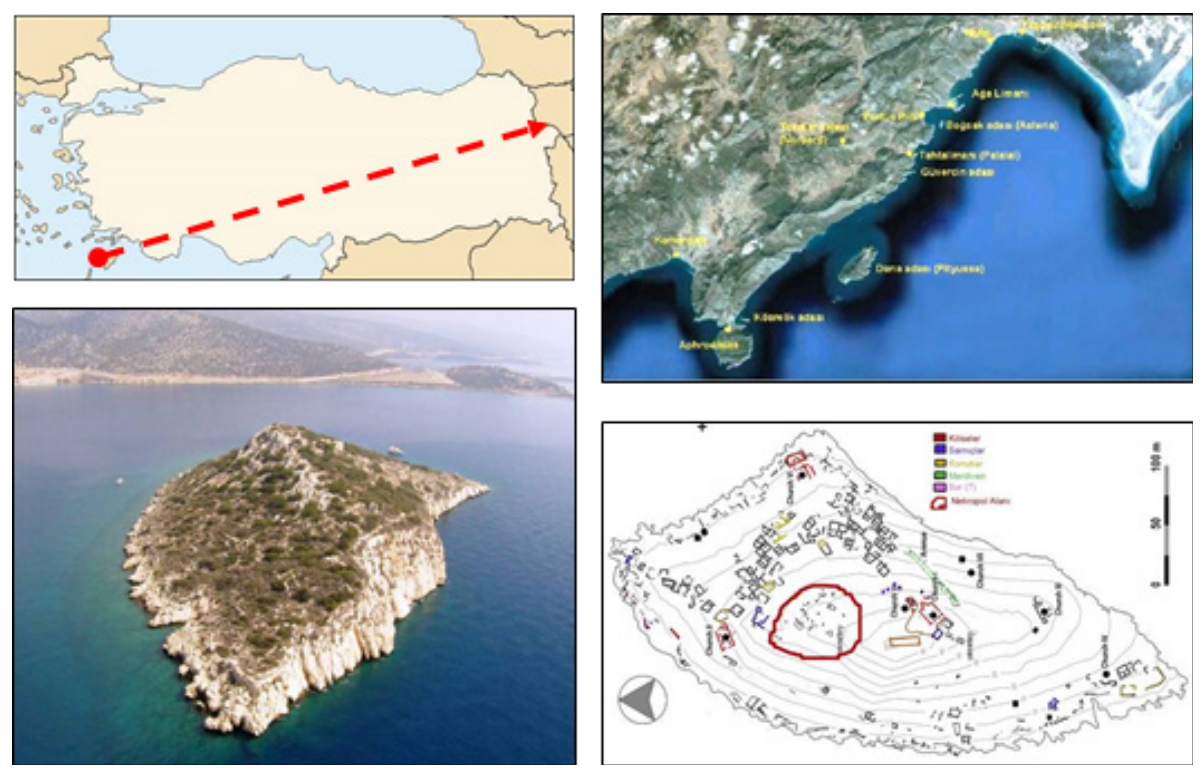

Görsel 5. Boğsak Adası: adanın konumu ve çevresinde tespit edilen antik yerleşmeler (üstte sağda), havadan görünüşü ve ada yerleşimi yapıları (altta sağda)

2010 yılından günümüze kadar Mersin ili, Silifke ilçesine bağlı İmamuşă̆ı köyü sınırlarındaki Boğsak Adası'nda, Doç. Dr. Günder Varinlioğlu tarafından yürütülen yüzey araştırma çalışmaları devam etmektedir (Varinlioğlu, 2011).

Adada devam eden yüzey araştırması ve mimariyi belirlemeye yönelik belgeleme çalışmalarında yapıların tipolojik özeliklerine ve fonksiyonlarına göre genel bir gruplama yapmak mümkündür. Buna göre yapılar; kiliseler, sarnıçlar, konutlar, merdivenler, adayı çevreleyen surlara ait olabilecek duvarlar ile bağımsız duvarlardan oluşmaktadır. Adanın kuzey, kuzeydoğu, batı ve güney yamaçlarının üst kesimlerinde geniş bir nekropol alanı da tespit edilmiştir (Şekil 5).

Adada Roma ve Erken Bizans dönemlerine tarihlenebilecek yerleşim kalıntıları bulunmaktadır (Şekil 5). Adadan Silifke Müzesi'ne taşınmış M.S. 5-6. yüzyıllara tarihlenen bir yazıtta, ada yerleşiminin adı Asteria olarak geçmektedir. Asteria'nın bir kente yaraşır yapılarla donatıldığını söyleyen bu yazıta dayanarak bu varsıl yerleşimin kent olmaya özenen, ancak bu statüyü edinememiş bir köy olduğu düşünülebilir (Varinlioğlu, 2011: 172). Son zamanlarda yapılan seramik araştırmalarında; adanın M.S. 2-3. yüzyıla tarihlenen yapılarında çok az, M.S. 3-7. yüzyıl sonuna kadar ise yoğun yaşamın olduğunu gösteren çok fazla sayıda seramik ele geçmiştir (Varinlioğlu, 2016: 94). Adanın Geç Antik dönem sonrasında (14-16. yüzyıllar) portulanlarında ve deniz haritalarında Boğsak koyu Portus Pini adıyla anılmakta, ancak adanın terkedilmiş olduğu ve konaklamaya elverişli olmadığı belirtilmektedir (Varinlioğlu, 2011: 172).

Kilikya bölgesinde yapılarda tuğla kullanımı yaygın değildir. Peschlow, bölgedeki tuğla kullanılan yapıları anlattığı çalışmasında Boğsak Adası'nda tespit edilen tuğla duvar örgülü sarnıç ile diğer tuğlalı yapılar hakkında bilgi verilmektedir (Peschlow, 2009: 77).

Boğsak Adası yerleşimine ait yapı malzemelerinin belgelenmesi ve araştırı masını amaçlayan bu çalışmalar; "Boğsak Adası Yerleşimi Yapılarına Ait Malzemelerin Arkeometrik Yönden Araşsııılması" adı altında yürütülen doktora tezinin konusunu oluşturmaktadır. Çalışmanın örneklemi 2013 yılında Yrd. Doç. Dr. Ali Akın AKYOL tarafından başlatılmıs, ilerleyen yıllarda da zenginleştirilerek sürdürülmüştür. Örnekler; Gazi Üniversitesi, Güzel Sanatlar Fakültesi, Kültür Varlıklarını Koruma ve Onarım Bölümü, Tarihi Malzeme Araştırma ve Koruma Laboratuvarı (MAKLAB) ile Ankara Üniversitesi Yer Bilimleri Uygulama ve Araştırma Merkezi (YEBiM) Laboratuvarları alet parkı kullanılarak analiz edilmiştir. Bu çalışma kapsamında ada yapılarına aittuğla/kiremitörneklerin fiziksel ve petrografik özellikleri ele alınmıştır.

\section{Yöntem ve Analizler}

\section{1 Örnekleme ve Belgelemeler}

Boğsak Adası yerleşimi yapıları arkeometrik analizleri kapsamında, yapılardan toplam 20 farklı tuğla ve kiremit örneği incelenmiştir. Tuğla/ kiremit örnekler kilise, sarnıç ve işlevi tam olarak bilinmeyen bağımsız mimari ögelerin duvarlarından örneklenmiştir (Şekil 5). Tuğla örnekleri yapılara göre dağıtılmış. Örnekler kiremitve tuğlalar olarak sınıflandırılmışıı (Tablo 1). Tuğla ve kiremitlerin duvar örgülerinde doğrudan ya da derz ve moloz dolgularda sıkışırma malzemesi olarak ikincil halde kullanımları tespit edilmiştir. 


\begin{tabular}{|l|l|c|}
\hline Ornekler & \multicolumn{1}{|c|}{ Açıllamalar } & Türü \\
\hline MBA-B I & Martiryondan sarnıçtan kuzey duvarın dış cephesinden (5) & Kiremit \\
\hline MBA-B2 & Martiryondan sarnıçtan kuzey duvarın dış cephesinden (5) & Kiremit \\
\hline MBA-B3 & Martiryondan sarnıçtan kuzey duvarın dı̧̧ cephesinden (5) & Kiremit \\
\hline MBA-B4 & Megaron tipli binanın batı duvarından (II) & Kiremit \\
\hline MBA-B5 & Martiryon kuzey cephe tabandan (13) & Kiremit \\
\hline MBA-B6 & Martiryon kuzey cephe tabandan (14) & Kiremit \\
\hline MBA-B7 & Martiryon kuzey cephe tabandan (I5) & Kiremit \\
\hline MBA-B8 & Kilise l'in doğusundaki sarnıçtan (25) & Tuğla \\
\hline MBA-B9 & Kilise l'in doğusundaki sarnıçtan (25) & Tuğla \\
\hline MBA-B 10 & Merdivenin üst kotundan (32) & Kiremit \\
\hline MBA-BII & Martiryonun kuzey doğusundaki ST002 nolu sarnıçtan (43) & Kiremit \\
\hline MBA-B 12 & Martiryonun kuzey doğusundaki ST002 nolu sarnıçtan (43) & Kiremit \\
\hline MBA-B 13 & Martiryonun kuzey doğusundaki ST002 nolu sarnıçtan (43) & Kiremit \\
\hline MBA-B I4 & Martiryonun kuzey doğusundaki ST002 nolu sarnı̧̧tan (43) & Kiremit \\
\hline MBA-B 15 & Moloz duvar örgüden (58) & Kiremit \\
\hline MBA-B 16 & Moloz duvar örgüden (58) & Kiremit \\
\hline MBA-B 17 & Moloz duvar örgüden (58) & Kiremit \\
\hline MBA-B 18 & Moloz duvar örgüden (58) & Kiremit \\
\hline MBA-B20 & Adanın güneybatı ucundaki ST024 yapısından (I04) & Tuğla \\
\hline MBA-B2I & Adanın güney ucundaki mekandan (I08) & Kiremit \\
\hline
\end{tabular}

Tablo I. Boğsak Adası yerleşimi kiremit ve tuğla örneklemi

Örnekler, arazide çalışma sırası ve sonrasında fotoğraflanarak belgelenmiş, gruplandırılarak kodlanmıştır. Kodlamada adanın ismini oluşturan "Mersin, Boğsak Adası Örnekleri baş harfleri ön kod (MBA), tuğla/kiremit örneklerin türü için de son ek olarak "B" harfi kullanılmıştır. Buna göre MBA-B1 örneği 1 no.lu tuğla/kiremit örneğini ifade etmektedir.

\subsection{Testler ve Analizler}

Boğsak Adası yapılarından örneklenen tuğla/kiremit örneklerine; birim hacim ağırlıkları (BHA), su emme kapasiteleri (SEK) ve gözenekliliklerini (P) belirlemeyi amaçlayan temel fiziksel testler uygulanmıştır. Gerçekleştirilen fiziksel testler, bu konuda standart oluşturmuş Jeoloji Mühendisliği bakış açısını yansıtan fiziksel test yöntemleri esas alınarak gerçekleştirilmiştir (Ulusay, Gökçeoğlu ve Binal, 2011: 58).

Boğsak Adası yapılarından örneklenen, tuğla/kiremit örneklerinin ince kesitleri hazırlanarak optik mikroskop ile incelenmiştir. Optik mikroskop inceleme yöntemleri ve mineralojik değerlendirmeler benzer çalışmalar dikkate alınarak gerçekleştirilmiştir (Kerr, 1977: 3-10; Rapp, 2002: 1340). Incelemelerde LEICA Research Polarizan DMLP Model alt ve üstten aydınlatmalı optik mikroskop kullanılmıştır. Fotoğraflamalar mikroskoba bağlı Leica DFC280 dijital kamerayla, değerlendirmeler de Leica Qwin Digital Imaging Programı kullanılarak yapılmıştır.

\section{Bulgular ve Değerlendirmeler}

\subsection{Fiziksel Testler}

Tuğla ve kiremit örneklere temel fiziksel testlerden birim hacim ağırlığı (BHA), gözeneklilik (P), su emme kapasitesi (SEK) ile petrografik ince kesit optik mikroskop analizi uygulanmıştır.

20 tuğla ve kiremit örneğinden 17'si kiremit, 3'ü de tuğla olarak gruplandırılmıştır. Örneklersarnıç, martiryon, mezarve işlevibelirlenemeyen bağımsız duvarların örgülerinden ve moloz dolgularından örneklenmiştir.

Boğsak Adası yerleşimi tuğla/kiremit örnekleri; üretim şartları, hammadde ve kil türü gibi özelliklerine göre değişen fiziksel özelliklere sahiptirler. Tuğla/kiremit örneklerin öncelikle doygun/kuru birim hacim ağırlıkları tespit edilmiştir. Yapısal özellikleri ile düşük yoğunluklu ve yüksek gözenekli örnekler daha dayanımsız durumda olan örneklerdir.

Buna göre tuğla/kiremit örneklerin doygun birim hacim ağırlıkları (tuğla ve kiremit türünden bağımsız olarak) 2,35-2,75 g/cm3 arasında (ort. 2,47 g/ $\mathrm{cm} 3$ ), kuru birim hacim ağıllıkları ise 1,48-2,00 g/cm3 arasında (ort. 1,80 $\mathrm{g} / \mathrm{cm} 3$ ), değişim göstermektedir Tuğlaların doygun birim hacim ağırlıkları 2,41-2,48 g/cm3 arasında, kuru birim hacim ağırlıkları 1,55-1,81 g/cm3 arasında değişmektedir (Tablo 2).

Boğsak Adası yapılarına ait tuğla/kiremit örneklerin fiziksel özelliklerinden su emme kapasiteleri (\% SEK) (tuğla ve kiremit türünden bağımsız olarak) \% 8,65-25,08 değerleri arasında (ort. \% 15,38) değişmektedir (Tablo 2).

Kiremit örneklerde su emme kapasitesi en düşük örnek MBA-B11 iken en yüksek MBA-B6, tuğla örneklerde en düşük su emme kapasitesine sahip örnek MBA-B8 iken en yüksek değer MBA-B9 örneğinde görülmektedir.

Tuğla/kiremit örneklerde gözeneklilik değerleri (tuğla ve kiremit türünden bağımsızolarak) \% 16,98-37,10 arasında (ort. \% 26,98) değişmektedir(Tablo 2). Tuğlaların gözeneklikleri de \%26,80-35,77 arasındaki değerlerdedir. Kiremit örneklerde gözenekliliği en düşük örnek MBA-B11 iken en yüksek MBA-B6, tuğla örneklerde en düşük gözenekliliğe MBA-B8 sahipken en 
yüksek gözeneklilik değerine MBA-B9 örneği sahiptir. (Tablo 2). Tuğla ve kiremit örneklerin fiziksel test verileri Özışık'a göre değerlendirildiğinde; $1,80 \mathrm{~g} / \mathrm{cm} 3$ civarında kuru birim hacim ağırlılıklarının (MBA-B11 dışında) yanında \%30'un üzerinde ve civarındaki değerlerde gözeneklilikleri ile tuğla ve kiremit örnekler ortalama kalitede üretilmiş, düşük ve ortalama kalitede dayanıma sahip örneklerdir (Özışık, 2000: 81) (Tablo 2). Tuğla ve kiremit örnekler oldukça değişken fiziksel özellikleri ile belli bir üretim standardını göstermemektedirler.

\begin{tabular}{|c|c|c|c|c|}
\hline Örnekler & BHA-Doygun $\left(\mathrm{g} / \mathrm{cm}^{3}\right)$ & BHA-Kuru $\left(\mathrm{g} / \mathrm{cm}^{3}\right)$ & SEK (\%) & $\mathbf{P}(\%)$ \\
\hline MBA-BI & 2,47 & 1,84 & 13,72 & 25,31 \\
\hline MBA-B2 & 2,51 & I,78 & $|6,5|$ & 29,34 \\
\hline MBA-B3 & 2,75 & 1,92 & 15,84 & 30,37 \\
\hline MBA-B4 & 2,46 & 1,69 & 18,52 & 31,32 \\
\hline MBA-B5 & 2,47 & 1,75 & 16,73 & 29,21 \\
\hline MBA-B6 & 2,35 & 1,48 & 25,08 & 37,10 \\
\hline MBA-B7 & 2,44 & 1,74 & 16,52 & 28,69 \\
\hline MBA-B8 & 2,47 & $|, 8|$ & 14,85 & 26,86 \\
\hline MBA-B9 & 2,41 & 1,55 & 23,10 & 35,77 \\
\hline MBA-BIO & 2,45 & $|, 8|$ & 14,36 & 26,01 \\
\hline MBA-BII & 2,36 & 1,96 & 8,65 & 16,98 \\
\hline MBA-BI2 & 2,54 & 1,60 & 22,99 & 36,87 \\
\hline MBA-BI 3 & 2,56 & 2,00 & 10,98 & 21,93 \\
\hline MBA-BI4 & 2,54 & 1,90 & 13,39 & 25,40 \\
\hline MBA-BI5 & 2,40 & 1,82 & 13,20 & 24,09 \\
\hline MBA-BI6 & 2,46 & 1,82 & 14,28 & 25,97 \\
\hline MBA-B I7 & 2,50 & 1,72 & 18,27 & 31,39 \\
\hline MBA-B I8 & 2,39 & 1,80 & 13,78 & 24,81 \\
\hline MBA-B20 & 2,48 & $|, 8|$ & 15,10 & 27,27 \\
\hline MBA-B2I & 2,55 & $1,9 \mid$ & 13,20 & 25,18 \\
\hline Ortalama & 2,47 & 1,80 & 15,38 & 26,98 \\
\hline
\end{tabular}

Tablo 2. Boğsak Adası yerleşimi kiremit ve tuğla örneklerinin fiziksel özellikleri

\subsection{Ince Kesit Optik Mikroskop Analizi}

Tuğla/kiremit örnekler petrografik ince kesit optik mikroskop analizlerine göre 11 grup altında sınıflandırımıştır. Örneklerin hamur yapısındaki agregalar petrografik olarak değerlendirildiğinde; yapılarında magmatik (damar), metamorfik ve sedimanter (karbonat ve kırıntılı) kökenli kayaç parçaları yer almaktadır. Damar kayaç diyabaz, sedimanterler kireçtaşı ve kırıntılı çört, metomorfik kayaç parçası da kuvarsittir. Mineraller ise kuvars, plajoklaz, biyotit, piroksen, serpantin, klorit, kalsit ve opak minerallerdir (Tablo 3 ve Görsel 6)

\begin{tabular}{|c|c|c|c|c|}
\hline $\begin{array}{c}\text { Tuğla } \\
\text { Örnek } \\
\text { Grupları }\end{array}$ & $\mathrm{T}\left({ }^{\circ} \mathrm{C}\right)$ & $\mathbf{P}(\%)$ & MTA (\%) & Kayaç ve Mineraller* \\
\hline Grup I & $800-850$ & 10 & 38 & $\mathrm{Q}, \mathrm{PI}, \mathrm{K}, \mathrm{TK}(\% \mathrm{I}, 5)$ \\
\hline Grup 2 & $800-850$ & 15 & 15 & Q,PI,K,C,By \\
\hline Grup 3 & $900-950$ & 4 & 7 & $\mathrm{Q}, \mathrm{PI}, \mathrm{C}, \mathrm{D}, \mathrm{OP}$ \\
\hline Grup 4 & $750-800$ & 12 & 22 & Q,PI,K,TK(\%2,5) \\
\hline Grup 5 & $800-850$ & 5 & 12 & $\mathrm{Q}, \mathrm{PI}, \mathrm{F}$ \\
\hline Grup 6 & $750-800$ & 5 & 10 & $\mathrm{Q}, \mathrm{Pl}, \mathrm{K}, \mathrm{C}, \mathrm{Q}, \mathrm{TK}(\% \mathrm{I}, 5)$ \\
\hline Grup 7 & $850-900$ & 10 & 25 & Q,PI,Ç,TK(\%2) \\
\hline Grup 8 & $850-900$ & 10 & 20 & Q,PI,By,Qs,Py,Op \\
\hline Grup 9 & $800-850$ & 7 & 12 & $\mathrm{Q}, \mathrm{K}, \mathrm{C}, \mathrm{Q}, \mathrm{TK}(\% \mid, 5)$ \\
\hline Grup 10 & $800-850$ & 10 & 8 & Q,By,C \\
\hline Grup II & $850-900$ & 10 & 25 & $\mathrm{Q}, \mathrm{PI}, \mathrm{S}, \mathrm{F}$ \\
\hline
\end{tabular}

(*) By: Biyotit, C: Kalsit, C:: Çört, D: Diabaz, F: Fosil ve Fosil Kavkıları, K: Kireçtașı, Op: Opak Mineraller, P. Plajiyoklas, Py: Piroksen, Q: Kuvars, Qs: Kuvarsit, S: Serpantin, T: Pişirim Sıcaklığı, TK: Tuğla Kirığı Parçaları

Grup I: MBA-BI, MBA-B7, MBA-B9, MBA-BI3, MBA-BI5

Grup 2: MBA-B2

Grup 3: MBA-B3, MBA-BIO, MBA-B/4

Grup 4: MBA-B4, MBA-B6, MBA-B20

Grup 5: MBA-B5

Grup 6: $M B A-B 8, M B A-B 16$

Grup 7: MBA-BII

Grup 8: MBA-B/2

Grup 9: MBA-BI7

Grup 10: MBA-B/8

\section{Grup II: MBA-B2I}

Tablo 3. Boğsak Adası yerleşimi kiremit ve tuğla örneklerinin petrografik özellikleri

Petrografikanalizde, hamurdokusuna, hamurunkaynaşmasıvegözenekliliği ile hamur içerisinde kil ve agregaların tür (türlerin fazları) ve dağııımlarına göre yaklaşık pişme derecesini belirlemek mümkün olabilmektedir (Tablo 3 ve Şekil 6) Genel anlamda tuğla ve kiremit örnekler; düşük/ortalama sıcaklıklarda $\left(750-950^{\circ} \mathrm{C}\right.$ 'de) pişirime uğramış gözenekli (\% 4-15) yapıdaki örnekler mineral ve kayaç türü yönünden zengin (matriksin \%7-38'i oranında agregalı) içeriklidir. Ayrıca örneklerin çoğunun (Grup 1, Grup 4, Grup 6, Grup 7 ve Grup 9) agrega yapısında, toplam agreganın \% 1,5-2,5'i arasında değişen oranlarda tuğla kırı̆̆ı parçaları da belirlenmiştir (Tablo 3 ve Görsel 6). 


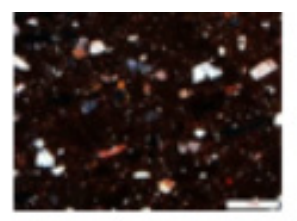

MBA-BI

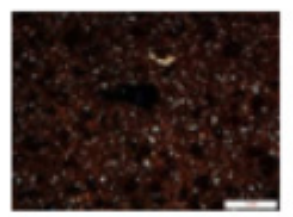

MBA-B5

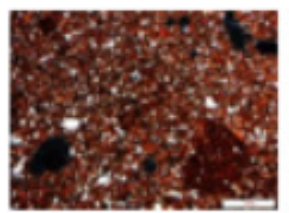

MBA-B9

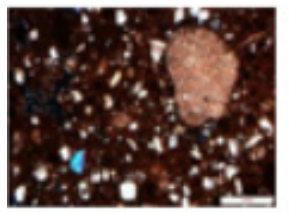

MBA-B I3

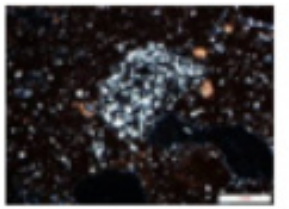

MBA-B I7

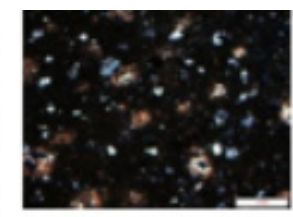

MBA-B2

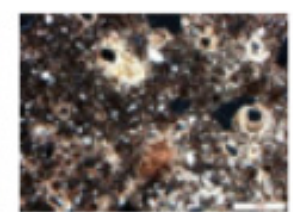

MBA-B6

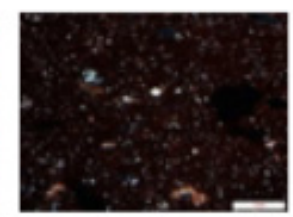

MBA-BI0

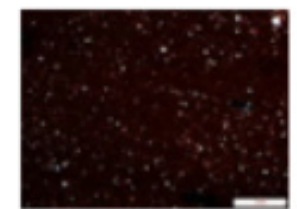

MBA-B I4

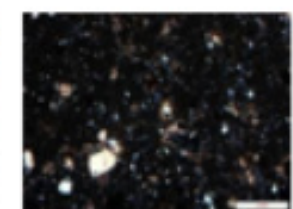

MBA-B I8

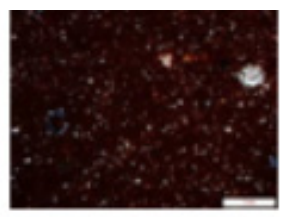

MBA-B3

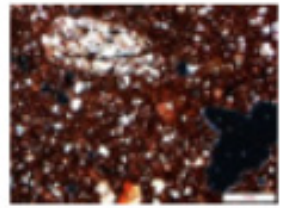

MBA-B7

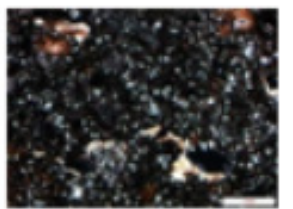

MBA-BII

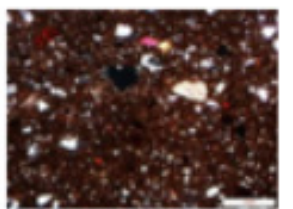

MBA-BI5

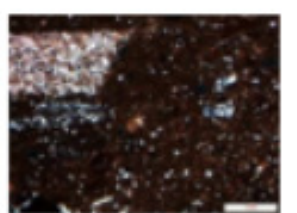

MBA-B20

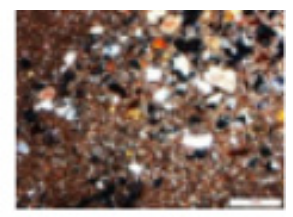

MBA-B4

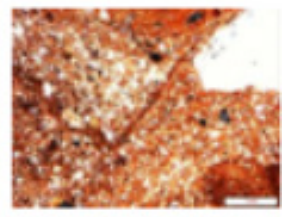

MBA-B8

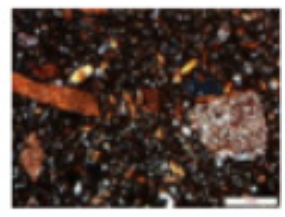

MBA-B I2

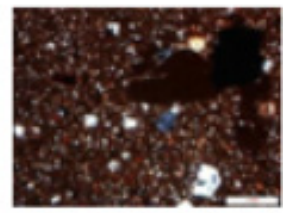

MBA-BI6

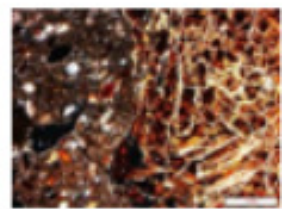

MBA-B2I
Görsel 6. Boğsak Adası yerleşimi kiremit ve tuğla örneklerinin ince kesit optik mikroskop analizi mikro fotoğrafları

Tuğla ve kiremit örneklerin bazılarının (MBA-B2 ve MBA-B18 örneklerinde) hamur yapısındaki boşluklarda ikincil karbonat oluşumları (rekristalize kalsitler) da görülmüştür. MBA-B3, MBA-B10, MBA-B14 ve MBA-B18 örnekleri agregalarında, uygun şekilde kurutulmadan, nemli pişirimden kaynaklanan agregada yönlenmeler görülmektedir. MBA-B11 örneğinde heterojen (iki tabakalı görünümde) pişirim görülmektedir. Ayrıca MBA-B5
(Grup 5) ve MBA-B21 (Grup 11) örneklerinin agrega içeriğinde fosil ve fosil kavkılarına da rastlanılmıştır (Tablo 3 ve Şekil 6).

Tuğla/kiremit örneklerinin agrega içerikleri kayaç kökenleri açısından değerlendirildiğinde; MBA-B3, MBA-B10 ve MBA-B14 örneklerinde mağmatik derinlik kayaçlarından diyabaz ve sedimanter kayaç parçası çört görülmüştür. MBA-B8, MBA-B12, MBA-B16 ve MBA-B17 örneklerinde metamorfik kayaçlardan kuvarsit, MBA-B3, MBA-B8, MBA-B10, MBA-B11, MBA-B14, MBA-B16, MBA-B17 ve MBA-B18 örneklerinde de sedimanter kayaç parçası çört belirlenmiştir. MBA-B21 no.lu örnekte ise serpantinit görülmektedir ve serpantinit magmatik kayaçların bir bozulma ürünüdür (Şekil 6).

Boğsak Adası yerleşimi yapılarından örneklenen tuğla ve kiremit örneklerin arkeometrik analizlerine yönelik bu çalışmada daha önce aynı bölgede gerçekleştirilen jeolojik araştırmalar da göz önünde bulundurulmuştur (Eroğlu, Akyol ve Varinlioğlu, 2017: 205-218; Gökten, 1976: 120; Gedik, Birgili, Yılmaz, ve Yoldaş, 1979: 15; Öztaş, 1993). Buna göre, ada ve çevresinde yerel formasyonu kireçtaşları oluşturmaktadır. Tuğla ve kiremit örneklerin petrografik yönden yakın çevre jeolojik formasyonu ile uyumlu olduğu anlaşılmıştır. Dikkat çeken bir başka özellik ise tuğla/kiremit örneklerin hamur yapısındaki bazı kayaç parçaları ada ve yakın çevresinde bulunmayan volkanik kökenli kayaçlardır. Bölge jeolojisi üzerine yapılan çalışmalara göre bu tür magmatik/volkanik kayaçlar; Mersin'in kuzeyinde Mersin Ofiyolitleri ile Silifke'nin kuzeyinde ve Mut-Ermenek arasında Göksu Vadisi içerisindeki ofiyolitik kayaç yapısı ile benzerlik göstermekte, en genel anlamda ada yerleşimi ve bu bölgeler arasındaki ilişkiyi malzeme bazında desteklemektedir.

\section{Tartışma Ve Sonuçlar}

Boğsak Adası yerleşimi yapısal malzemelerinden çalışmanın konusunu oluşturan tuğla ve kiremit örnekler üzerinde temel fiziksel testler (birim hacim ağırlığı, su emme kapasitesi ve gözeneklilik) ile ince kesit optik mikroskop analizi gerçekleştirilmiştir. Tuğla ve kiremit örneklerin fiziksel test verileri değerlendirildiğinde; düşük/ortalama birim hacim ağırlıkları ve yüksek değerlerde gözeneklilikleri ile örneklerin düşük/ortalama kalitede üretildikleri anlaşılmaktadır. Tuğla ve kiremit örnekler oldukça değişken fiziksel özellikleri ile belirli bir üretim standardını göstermemektedirler. Bu durum yapıların fonksiyonları (kilise, sarnıç ve işlevi belirlenemeyen duvar 
örgüler) ele alındığında da değişim göstermemektedir.

Petrografik ince kesit optik mikroskop analizlerine göre 17 kiremit örneği 11 grup altında, 3 tuğla örneği de (MBA-B8, MBA-B9 ve MBA-B20) 3 grup altında sınıflandırılmıştır. Örneklerin hamur yapısındaki agregalar petrografik olarak değerlendirildiğinde; yapılarında magmatik (damar), metamorfik ve sedimanter (karbonat ve kırıntılı) kökenli kayaç parçalarının yer aldığı belirlenmiştir. Petrografik analizler gözenekli yapıdaki (\% 4-15) örneklerin düşük/ortalama sıcaklıklarda $\left(750-950^{\circ} \mathrm{C}\right.$ 'de) pişirime uğradığını göstermiştir.

Tuğla ve kiremit örneklerin hamur yapısında farklı türde mineral ve kayaç türleri bulunmaktadır. Bu durum örneklerin üretimine ait hammadde kaynakları hakkında önemli bilgiler vermektedir. Ada ve çevresinde yerel formasyonu kireçtaşları oluşturmaktadır. Tuğla ve kiremit örneklerin petrografik yönden yakın çevre jeolojik formasyonu ile büyük oranda uyumlu olduğu anlaşılmıştır. Denizel kökenli 2 grup örneğin agrega yapısında fosil ve fosil kavkıları yer almaktadır. Bununla beraber bazı tuğla/ kiremit örneklerin (Grup 3 ve Grup 11) hamur yapısındaki serpantinit ve diabaz gibi kayaç parçaları, ada ve yakın çevresinde bulunmayan volkanik kökenli kayaçlardır. Bölge jeolojisi üzerine yapılan çalışmalara göre bu tür magmatik/volkanik kayaçlar; Mersin'in kuzeyinde Mersin Ofiyolitleri ile Silifke'nin kuzeyinde ve Mut-Ermenek arasında Göksu Vadisi içerisindeki ofiyolitik kayaç yapısı ile benzerlik göstermekte, en genel anlamda ada yerleşimivebubölgelerarasındakiilişkiyimalzemebazında desteklemektedir.

Tuğla ve kiremit örneklerin bazılarının hamur yapısındaki boşluklarda ikincil karbonat (rekristalizasyon) oluşumları ile uygun şekilde kurutulmadan, nemli pişirimden kaynaklanan agregada yönlenmeler ve tabakalı pişirim katları da görülmektedir. Ayrıca örneklerin yarıya yakınının agrega yapısında, mukavemeti artırmak adına tuğla kırı̆̆ı parçalarının da eklenmiş olduğu anlaşılmaktadır.

Antik dünyada tuğla üretimi Romalı mimar Vitruvius'un yaşadığı M.S. 1. yüzyıldan itibaren bilinmektedir. Gerçekleştirilen arkeometrik çalışmalar; Boğsak Adası Geç Antik dönem yerleşimi yapılarında yapısal ve derz dolgularında kullanılmış olan tuğla ve kiremitlerin daha önceki dönemlerde belirlenen üretim standartlarının oldukça ötesinde ve daha düşük bir üretim teknolojisini yansıttığını göstermiştir. 


\section{Kaynakça}

Adam, J.P. (1999). Roman Building: Materials and Techniques. London and New

Akyol, A.A., Yıldırım, E.E., Erten, E. ve Kadıoğlu, Y.K. (20I3). “Olba Kazı Kiremit Örnekleri Arkeometrik Çalışmaları”, Seleucia ad Calycadnum, Olba Kazısı Yayınları, Sayı: III-20I3. s. 25I-269.

Akyol, A.A., Kadıoğlu, Y.K. ve Özyıldırım, M. (20/4). "Alahan Manastırı Kiremit Örnekleri Arkeometrik Çalısmaları", Seleucia ad Calycadnum, Olba Kazısı Yayınları, Sayı: IV-20I4. s. $175-191$.

Bakırer, Ö. (198I). Selçuklu Öncesi ve Selçuklu Dönemi Anadolu Mimarisinde Tuğla Kullanımı. Ankara: Orta Doğu Teknik Üniversitesi.

Benzel, K. (2010). Art of The Ancient Near East: A Resource For Educators. New York: Metropolitan Museum of Art.

Dodge, H. (1984). "The Use of Bricks in Roman Asia Minor", Yayla 5, Fifth Report of the Northern Society for Anatolian Archaeology, s. 10-15.

Eroğlu, M., Akyol, A.A. ve Varinlioğlu, G. (20I7). "Boğsak Adası Yerleşimi Yapılarında Arkeometrik Çalışmalar”, 32. Arkeometri Sonuçları Toplantısı Bildiri Kitabı, T.C. Kültür ve Turizm Bakanlı̆̆ı Kültür Varlıkları ve Müzeler Genel Müdürlüğü Yayın No: I77, s. 205218 .

Filippi, G. (2007). The "Horace's Villa" Brickstamps And The Brick Production of The Central Anio River Valley". Frischer, B., Crawford, J.W., and Simone, M.D (Eds.) The "Horace's Villa" Project 1997-2003 Volume, (2 vol Set): Report on New Fieldwork and Research. British Archaeological Reports, s. 197-219.

Gedik, A., Birgili Ş,. Yılmaz H. ve Yoldaş R. (1979). "Mut-Ermenek-Silifke Yöresinin Jeolojisi ve Petrol Olanakları”, Türkiye Jeoloji Kurumu Bülteni, c. 22, s. 7-26.

Gökten, E. (1976). "Silifke Yöresinin Temel Kaya Birimleri ve Miyosen Stratigrafisi”, Türkiye Jeoloji Kurumu Bülteni, Ağustos , c. 19, s. I/7-I 26.

Günsenin, N. (1996). “I 994 Yılı Marmara Adaları Sualtı Araştırması, Araştırma Sonuçları Toplantısı. XIII. Araştırma Sonuçları Toplantısı: 29 Mayıs - 2 Hazıran 1995 Ankara, s. 355-374.
Işık, Ö. (20I0). Konya Şerafeddin Camisi Yakınındaki Türbenin Tuğla Duvar Malzemesinin Arkeometrik Yönden Araștırılması. Çukurova Üniversitesi Fen Bilimleri Enstitüsü Arkeometri Anabilim Dalı, Yayınlanmamış Yüksek Lisans Tezi, Adana.

Kamm, A. ve Graham, A. (20/4). The Romans: An Introduction. Routledge.

Kerr, P.F. (1977). “Optical Mineralogy”, McGraw-Hill Co. First Ed'n., New York.

Mattingly, D.J. ve Salmon, J. (2002). Economies Beyond Agriculture in the Classical World. Routledge.

Mergen, E.M. (20I0). Kuşadası, Kadıkalesi’nde Bizans Dönemine Ait Duvarlarda Görülen Malzeme ve Teknik. Ege Üniversitesi Sosyal Bilimler Enstitüsü Bizans Anabilim Dalı Yayınlanmamış Yüksek Lisans Tezi.

Özışı, G. (2000). Yapı Mühendisliğinde Tuğla Elemanlar ve Yapı Sistemleri. İstanbul: Birsen Yayınevi.

Öztaş, T. (1993). "Boğsak Karst Kaynağı (Mersin-Taşucu) Örneğinde Bir Karst Kaynağı ve Akiferinin Jeohidrolojik Analizi”, Jeoloji Mühendisliği, c. 42, s. 5- 4.

Peschlow, U. (2009). Die Zisternen von Meriamlik. Fragen zu Bau- und Mauertechnik im Bezirk von Ayatekla in: Eichner, I., Tsamakda, V. (Hrg.), Syrien und seine Nachbarn von der Spätantike bis in die islamische Zeit (Wiesbaden 2009), s. 57-80.

Rapp, G. (2002). Archaeomineralogy. Berlin: Springer-Verlag.

Roaf, M. (1996). Mezopotamya ve Eski Yakındoğu. İstanbul: İletişim Yayınları.

Şimşek, O. (2003). Yapı Malzemesi. İstanbul: 2. Baskı, BetaYayınevi.

Şişman, C.B, Kocaman, i. ve Gezer, E. (2006). "Tekirdağ Yöresinde Üretilen ve Tarımsal Yapılarda Yaygın Olarak Kullanılan Tuğlanın Fiziksel ve Mekanik Özellikleri Üzerine Bir Araştırma", Tekirdağ Ziraat Fakültesi Dergisi, vol:3 sayı, I, s. 32-40.

Ulusay, R., Gökçeoğlu, C. ve Binal, A. (20II). Kaya Mekaniği Laboratuvar Deneyleri. Ankara: TMMOB Jeoloji Müh. Odası Yayınları: s. 58.

Varinlioğlu, G. (20II). “Boğsak Adası'nda Yerleşim Arkeolojisi (2010)” 29. Araştırma Sonuçları Toplantısı 2. Cilt, s. I7I-I84, Malatya. 
Varinlioğlu, G. (20I2). "Boğsak Adası ve Güney Isauria Kıyıları Yüzey Araştırması (20I I)”, 30. Araştırma Sonuçları Toplantısı I. Cilt, s. 37I-379, Çorum.

Varinlioğlu, G. (20I6). “Boğsak Arkeolojik Yüzey Araştırması (20I5)”, 34. Araştırma Sonuçları Toplantısı I. Cilt, s. 9I-III, Edirne.

Vitruvius. (1993). Mimarlık Üzerine On Kitap. (çev. Suna Güven) Şevki Vanlı Mimarlık Vakfi

\section{Görsel Kaynakları}

Görsel I. (a),( b) https://metmuseum.org/art/collection/search/544649

Görsel I. (c), http://cojs.org/leather_scroll-_quota_for_brick-making__I274_bce/

Görsel 2. (a) http://www.gettyimages.com/license/555070107

Görsel 2. (b) Benzel, K., (2010). Art Of The Ancient Near East: A Resource For Educators. New York: Metropolitan Museum Of Art, s. I.

Görsel 3. (a) http://www.sanatinoykusu.com/antik-romanin-olum-arenasi-collesium/

Görsel 3. (b). http://blogs.ashmolean.org/latininscriptions/20/5/06//2/she-built-rome-adifferent-kind-of-imperial-woman/

Görsel 4. (a) Adam, J.-P. (1999). Roman Building: Materials and Techniques. London and New York,s. 294

Görsel 4. (b) Çalışma arşivinden

Görsel 5. Çalışma arşivinden 